INTERVENTIONAL CARDIOLOGY AND SURGERY

\title{
One year results of the Middlesbrough early revascularisation to limit infarction (MERLIN) trial
}

\author{
A G C Sutton, P G Campbell, R Graham, D J A Price, J C Gray, E D Grech, J A Hall, A A Harcombe, \\ R A Wright, R H Smith, J J Murphy, A Shyam-Sundar, M J Stewart, A Davies, N J Linker, \\ M A de Belder
}

Heart 2004;91:1330-1337. doi: 10.1136/hrt.2004.047753

See end of article for authors' affiliations

Correspondence to: Dr Andrew G C Sutton, Cardiothoracic Division The James Cook University Hospital, Marton Rd, Middlesbrough TS4 3BW UK; Andrew.Sutton@stees. nhs.uk

Accepted

12 November 2004
Objective: To report one year results of the MERLIN (Middlesbrough early revascularisation to limit infarction) trial, a prospective randomised trial comparing the strategy of coronary angiography and urgent revascularisation with conservative treatment in patients with failed fibrinolysis complicating ST segment elevation myocardial infarction (STEMI). The 30 day results have recently been published. At the planning stage of the trial, it was determined that follow up of trial patients would continue annually to three years to determine whether late benefit occurred.

Subjects: 307 patients who received a fibrinolytic for STEMI but failed to reperfuse early according to previously described ECG criteria and did not develop cardiogenic shock.

Methods: Patients were randomly assigned to receive either emergency coronary angiography with a view to proceeding to urgent revascularisation (rescue percutaneous coronary intervention ( $\mathrm{rPCl}$ ) arm) or continued medical treatment (conservative arm). The primary end point was all cause mortality at 30 days. The secondary end points included the composite end point of death, reinfarction, stroke, unplanned revascularisation, or heart failure at 30 days. The same end points were evaluated at one year and these results are presented.

Results: All cause mortality at one year was similar in the conservative arm and the $\mathrm{rPCl}$ arm $(13.0 \% \mathrm{v}$ $14.4 \%, p=0.7$, risk difference (RD) $-1.4 \%, 95 \%$ confidence interval $(\mathrm{Cl})-9.3$ to 6.4$)$. The incidence of the composite secondary end point of death, reinfarction, stroke, unplanned revascularisation, or heart failure was significantly higher in the conservative arm $157.8 \%$ v $43.1 \%, p=0.01, \mathrm{RD} 14.7 \%, 95 \% \mathrm{Cl}$ $3.5 \%$ to $25.5 \%)$. This was driven almost exclusively by a significantly higher incidence of subsequent unplanned revascularisation in the conservative arm $(29.9 \%$ v $12.4 \%, \mathrm{p}<0.001, \mathrm{RD} 17.5 \%, 95 \% \mathrm{Cl}$ $8.5 \%$ to $26.4 \%$ ). Reinfarction and clinical heart failure were numerically, but not statistically, more common in the conservative arm $(14.3 \% v 10.5 \%, p=0.3, \mathrm{RD} 3.8 \%, 95 \% \mathrm{Cl}-3.7$ to 11.4 , and $31.2 \% v$ $26.1 \%, \mathrm{p}=0.3, \mathrm{RD} 5.0 \%, 95 \% \mathrm{Cl}-5.1$ to 15.1$)$. There was a strong trend towards fewer strokes in the conservative $\operatorname{arm}(1.3 \%$ v $5.2 \%, p=0.06, \mathrm{RD}-3.9 \%, 95 \% \mathrm{Cl}-8.9$ to 0.06$)$.

Conclusion: At one year of follow up, there was no survival advantage in the $\mathrm{rCCl}$ arm compared with the conservative arm. The incidence of the composite secondary end point was significantly lower in the $\mathrm{rPCl}$ arm, but this was driven almost entirely by a highly significant reduction in the incidence of further revascularisation.
F brinolytic treatment for ST segment elevation myocardial infarction (STEMI) results in restoration of antegrade flow in the infarct related vessel soon after administration on only $50 \%$ of occasions. ${ }^{1}$ For all patients recorded in MINAP (myocardial infarction national audit project) between 1 April 2002 and 31 March 2003, almost 27000 doses of fibrinolytic were administered (JS Birkhead, personal communication, 2004). Therefore, the number of patients with failed fibrinolysis ("failed reperfusion") is high. The best management of this condition is unclear. Options include rescue percutaneous coronary intervention ( $\mathrm{rPCI}$ ); further administration of fibrinolytic; administration of other adjunctive pharmacological agents, for example, a glycoprotein IIb/IIIa inhibitor; insertion of an intra-aortic balloon pump; and combinations of the above or none of the above.

There are few data to inform guidelines on management. Most of the available data on rPCI are from retrospective analyses of non-randomised cohorts of patients (or from patients entered into randomised trials where randomisation occurred before the diagnosis of failed fibrinolysis). ${ }^{2-1}$ Patients described in these series are inevitably heterogeneous, the 30 day or hospital mortality ranges between $2-12 \%$, and as with all such series it is not clear which patients with failed fibrinolysis were not offered rPCI or what happened to them. Nonetheless, in patients with failed fibrinolysis undergoing uncomplicated rPCI with restoration of normal antegrade flow, clinical outcomes appear superior to those of historical patients who fail to achieve normal flow after administration of a fibrinolytic and are managed medically.

\footnotetext{
Abbreviations: $C A B G$, coronary artery bypass grafting; $\mathrm{Cl}$, confidence interval; DANAMI-2, second Danish multicentre randomised study on fibrinolytic therapy versus acute coronary angioplasty in acute myocardial infarction; GUSTO-1, global utilisation of streptokinase and tissue plasminogen activator for occluded coronary arteries; MERLIN, Middlesbrough Early Revascularisation to Limit Infarction; MINAP, myocardial infarction national audit project; $\mathrm{PCl}$, percutaneous coronary intervention; PRAGUE, primary angioplasty in patients transferred from general community hospitals to specialised PTCA units with or without emergency thrombolysis; PRAIS-UK, prospective registry of acute ischaemic syndromes in the UK; RESCUE, randomised evaluation of salvage angioplasty with combined utilisation of end points; $R D$, risk difference; $\mathrm{rPCl}$, rescue percutaneous coronary intervention; SAMI, streptokinase angioplasty myocardial infarction; STEMI, ST segment elevation myocardial infarction; TIMI, thrombolysis in myocardial infarction
} 
Only one previous dedicated randomised trial has compared rescue angioplasty with conservative treatment for failed fibrinolysis. ${ }^{12}$ In the early 1990s, Ellis et al ${ }^{12}$ compared rescue angioplasty with continued conventional medical treatment in patients with a first anterior myocardial infarction. They reported a trend towards a reduction in the incidence of the non-prespecified end point of 30 day death or severe heart failure in the rescue arm $(6 \% \vee 17 \%$, $\mathrm{p}=0.05)$. However, the overall low incidence of adverse end points in both arms of the trial raises the question of applicability of the trial results to the whole population of patients with failed fibrinolysis complicating STEMI.

The MERLIN (Middlesbrough early revascularisation to limit infarction) trial was designed to assess the role of rPCI in the modern angioplasty era and is a prospective randomised trial comparing this treatment modality with conservative treatment in patients with failed fibrinolysis. The 30 day clinical outcomes have recently been published. ${ }^{13}$ There was no difference in the primary end point of 30 day all cause mortality between the conservative and rescue arms $(11 \% \mathrm{v}$ $9.8 \%, \mathrm{p}=0.7$, risk difference $(\mathrm{RD}) 1.2 \%, 95 \%$ confidence interval (CI) -5.8 to 8.3 ). Left ventricular function at 30 days was similar. The conservative arm had a significantly higher incidence of the composite secondary end point of death, reinfarction, unplanned revascularisation, stroke, or clinical heart failure ( $50 \% v 37.3 \%, \mathrm{p}=0.02, \mathrm{RD} 12.7 \%, 95 \% \mathrm{CI} 1.6$ to 23.5). This was driven by a significant excess of unplanned subsequent revascularisation in the conservative arm $(20 \% \mathrm{v}$ $6.5 \%, \mathrm{p}<0.01, \mathrm{RD} 13.6 \%, 95 \%$ CI 6.2 to 21.4$)$. Patients in the rPCI arm had more strokes ( $4.6 \% v 0.6 \%, \mathrm{p}=0.03$, RD 3.9\%, $95 \%$ CI 0.5 to 8.6 ) and more transfusions ( $11.1 \% \vee 1.3 \%$, $\mathrm{p}<0.001$, RD $9.8 \%, 95 \%$ CI 4.9 to 19.9). One interpretation of the 30 day data is that rPCI need not be routinely applied in a patient with failed fibrinolysis complicating STEMI as long as reinfarction and post-infarction unstable angina are aggressively sought and treated. However, annual follow up of trial patients for three years was planned to determine whether rPCI was associated with late benefit.

\section{METHODS}

The study methods have previously been described.$^{13}$ In brief, patients with STEMI and evidence of failure to respond to the administration of a fibrinolytic based on ECG analysis constituted the trial population. Three hundred and seven patients fulfilling the trial entry criteria were randomly assigned to either rPCI or conservative treatment. Exclusion criteria were cardiogenic shock; confounding features on the pre-fibrinolysis ECG preventing ST segment reduction analysis; reinfarction in the same ECG territory within two months of an original infarction; absent femoral pulses; pregnancy; and presence of significant coexisting pathology likely to affect prognosis during the follow up period.

Patients in the rPCI arm were transferred urgently to the cardiac catheterisation laboratory at The James Cook University Hospital as soon as the 60 minute ECG confirmed persistent ST segment elevation and consent had been obtained. Coronary angiography was performed from any arterial access point and rPCI was attempted if considered appropriate. Patients in the conservative arm received standard medical treatment after the administration of a fibrinolytic. Early crossover to the rPCI arm was not allowed except in the case of development of cardiogenic shock.

Two experienced echocardiographers (DJP and RG) formally assessed left ventricular function at 30 days and six months. All images were analysed by a single observer (RG) who was blinded to the treatment strategy.

\section{End points and definitions}

The primary end point was all cause mortality at 30 days.
Table 1 Demographic details

\begin{tabular}{lll}
\hline & \multicolumn{2}{l}{ Treatment arm } \\
\cline { 2 - 3 } Characteristic & $\begin{array}{l}\text { Conservative } \\
\text { (n= } 154)\end{array}$ & $\begin{array}{l}\text { rPCI } \\
\text { (n= }=153)\end{array}$ \\
\hline Men (\%) & $114(74 \%)$ & $108(71 \%)$ \\
Age (years) & $62.7(10.9)$ & $63.0(11.2)$ \\
History of hypertension & $47(30.5 \%)$ & $62(40.5 \%)$ \\
History of diabetes & $23(14.9 \%)$ & $18(11.8 \%)$ \\
Insulin treatment & $7(4.5 \%)$ & $4(2.6 \%)$ \\
Known hyperlipidaemia & $24(15.6 \%)$ & $29(19.0 \%)$ \\
Total cholesterol on admission (mmol/l) & $5.54(1.17)$ & $5.82(1.32)$ \\
Blood glucose on admission (mmol/I) & $8.9(3.0)$ & $9.0(3.3)$ \\
Current smoker & $57(37.0 \%)$ & $64(41.8 \%)$ \\
Former smoker & $51(33.1 \%)$ & $45(29.4 \%)$ \\
Previous Ml & $20(13.0 \%)$ & $17(11.1 \%)$ \\
Anterior Ml & $62(40.3 \%)$ & $74(48.4 \%)$ \\
Pain to lysis time (min) & $170(96)$ & $180(120)$ \\
Lysis to laboratory time (min) & NA & $146(37)$ \\
Pain to laboratory time (min) & NA & $327(121)$ \\
\hline
\end{tabular}

Data are mean (SD) or number (\%).

$\mathrm{MI}$, myocardial infarction; NA, not applicable; $r \mathrm{PCl}$, rescue percutaneous coronary intervention.

The secondary end points were as follows:

- Composite of death, reinfarction, stroke, heart failure, or clinically driven unplanned revascularisation within 30 days. Reinfarction was defined by a repeat episode of ischaemic chest pain after recovery from the initial event, associated with typical ST segment re-elevation on the ECG and lasting for $>30$ minutes despite treatment with opiate and nitrate. Stroke was defined by any new neurological deficit lasting $>24$ hours; computed tomography was performed where possible. Heart failure was defined by the requirement for diuretic treatment in the presence of typical characteristics on chest radiography, or auscultatory crackles extending at least one third of the way up the lung fields without a history of chronic pulmonary disease, or a third heart sound with persistent tachycardia. Unplanned revascularisation was defined by any catheter based or surgical intervention in the conservative arm and any additional revascularisation procedure in the rPCI arm that was not planned after the initial coronary angiogram.

- Left ventricular function at 30 days assessed by the regional wall motion index.

It was predetermined that the primary end point of all cause mortality and the components of the secondary composite end point would be reassessed annually up to three years after trial entry.

Procedural success in the rescue angioplasty arm was defined by the presence of TIMI (thrombolysis in myocardial infarction) grade 2 or 3 flow in the infarct related vessel with a less than $50 \%$ residual stenosis and by no requirement for emergency coronary artery bypass grafting (CABG) as the result of a complication of percutaneous coronary intervention (PCI), with the patient transferred back to the coronary care unit.

\section{Statistical methods}

All end points were analysed on an intention to treat basis. Groups were statistically compared by $\chi^{2}$ analysis for the categorical variables with calculation of RD and 95\% CIs. Fisher's exact test was used where expected values were less than 5. Survival and survival without occurrence of one (or more) of the individual end points were plotted on Kaplan-Meier curves. The statistical package used was StatsDirect Statistical Software (StatsDirect Ltd, Sale, UK). 


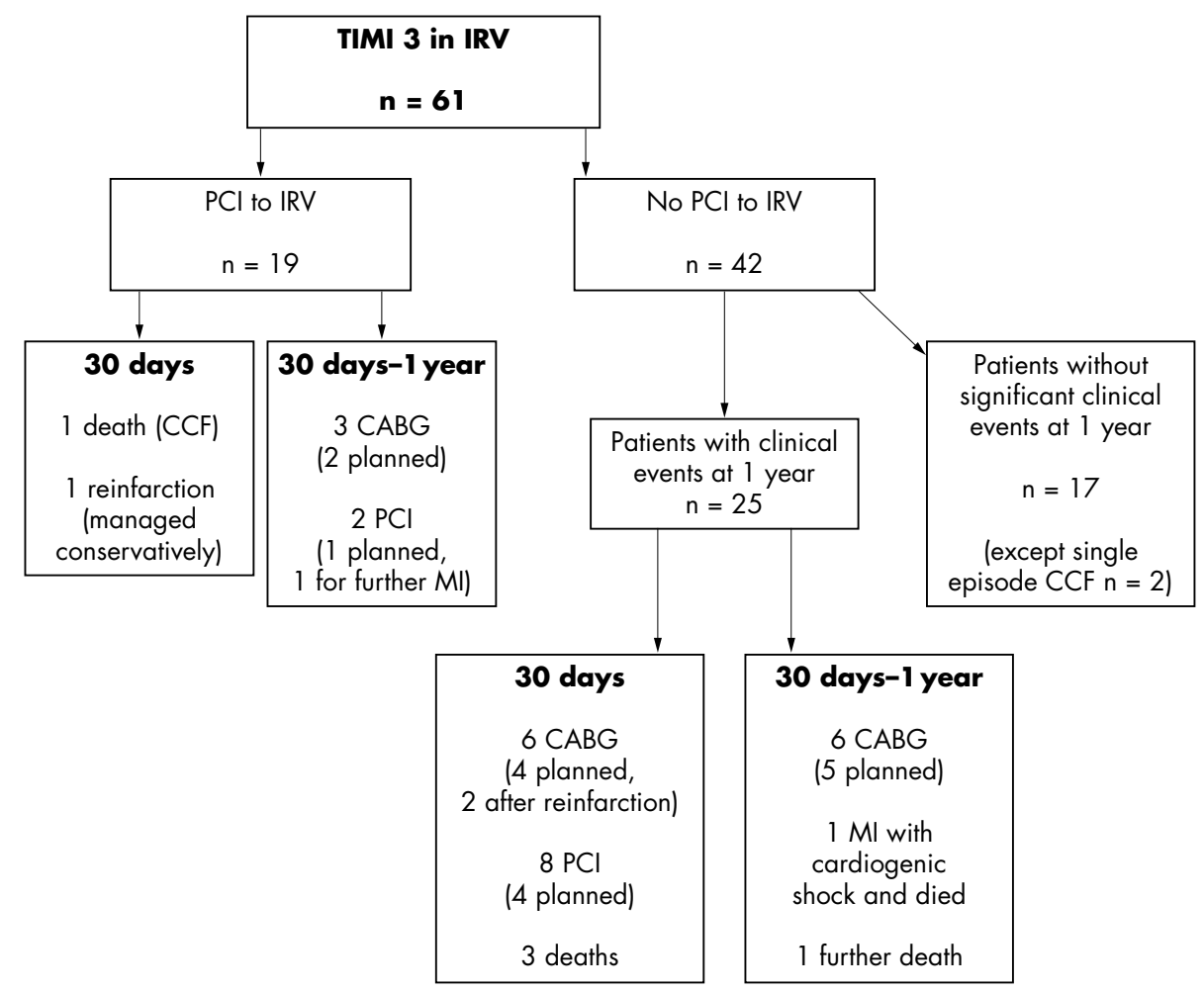

Figure 1 Outcome of patients in the rescue percutaneous coronary intervention (rPCI) arm with TIMI (thrombolysis in myocardial infarction) 3 flow at angiography. $C A B G$, coronary artery bypass grafting; CCF, clinical cardiac failure; IRV, infarct related vessel; $\mathrm{Ml}$, myocardial infarction.

\section{RESULTS}

The two groups were well matched (table 1).

In the rPCI arm, initial flow in the infarct related vessel was TIMI $3(\mathrm{n}=61)$ and TIMI $<3(\mathrm{n}=88)$. Four patients did not have the coronary anatomy visualised for clinical or technical reasons. rPCI was performed in 82 of 88 patients with TIMI $<3$ flow and a successful outcome was achieved in 77 of these patients (94\%).

Of the six with TIMI $<3$ not undergoing rPCI, one patient developed TIMI 3 flow in the infarct related vessel after coronary angiography and was referred for elective CABG but was admitted with unstable symptoms and underwent urgent CABG (day 209). Another was advised to have urgent CABG but declined (and died on day 3). One was treated with an intra-aortic balloon pump with a plan for interval CABG but was readmitted unstable and underwent urgent CABG (day 70). A fourth underwent planned in-house CABG. One had a distally occluded small obtuse marginal and was managed medically. The sixth patient with anterior STEMI was pain-free and haemodynamically stable at angiography. The left anterior descending coronary artery was patent with a moderate proximal stenosis (with normal flow) and a non-dominant right coronary artery with proximal collaterals to the left anterior descending artery territory was occluded. A medical strategy was pursued.

Of the patients with initial TIMI 3 flow $(n=61)$, 19 had PCI to the infarct related vessel and 42 did not (fig 1). All interventions in the 19 patients with TIMI 3 flow were technically successful but one patient died of heart failure (day 1) and another patient had a reinfarction (day 24) after intervention to a thrombus laden vein graft and was managed medically. Five of the 19 underwent revascularisation after 30 days: two elective CABG; one elective PCI; one urgent CABG (day 121); and one urgent PCI for infarction in a different territory (day 329).

Of the 42 patients with TIMI 3 flow in the infarct related vessel who did not undergo immediate PCI after angiography, 17 sustained no significant clinical events more serious than an episode of clinical heart failure $(\mathrm{n}=2)$ up to one year's follow up.

Twelve of the 42 underwent revascularisation by CABG, of which nine were planned procedures after initial coronary angiography and three were emergency operations: one patient with severe triple vessel disease sustained probable reinfarction and was treated with urgent intra-aortic balloon pump and CABG (day 3); one patient scheduled for elective CABG sustained reinfarction (day 1), which was managed medically because of severe tortuosity of the aorta and very difficult engagement of the coronaries, and was then discharged but readmitted and underwent urgent CABG (day 23); and one patient underwent urgent CABG for unstable angina with no evidence of infarction (day 169). None of these patients died.

Eight of the 42 patients underwent revascularisation by PCI within 30 days of trial enrolment. Four had planned procedures (one 82 year old with severe triple vessel disease who was turned down for CABG; one patient with severe triple vessel disease who declined CABG; one patient with heavy thrombus in the culprit right coronary artery, but normal flow, who underwent a period of anticoagulation before planned culprit vessel PCI several days later; one patient with a modest stenosis in the infarct related vessel undergoing PCI to a non-culprit vessel). Four procedures were unplanned (two for reinfarction, one for post-infarction angina, and one for an adverse exercise tolerance test). None died.

Five of the 42 died by one year. Three patients died by 30 days, all of whom had not undergone subsequent revascularisation (one 86 year old; one 72 year old with severe aortic stenosis; and one 39 year old with a postmortem examination confirming the revised clinical diagnosis of acute myocarditis). Two died after 30 days (one 81 year old on day 276; and one on day 313 after further myocardial infarction complicated by cardiogenic shock).

One hundred and thirty patients in the rPCI arm $(87.2 \%$ of those undergoing angiography) left the catheterisation laboratory with TIMI 3 flow in the infarct related vessel. 
Table 2 One year end points

\begin{tabular}{|c|c|c|c|c|}
\hline \multirow[b]{2}{*}{ End point } & \multicolumn{2}{|c|}{ Treatment arm } & \multirow[b]{2}{*}{ p Value } & \multirow[b]{2}{*}{ RD \% $(95 \% \mathrm{Cl})$} \\
\hline & $\begin{array}{l}\text { Conservative } \\
(n=154)\end{array}$ & $\begin{array}{l}r P C l \\
(n=153)\end{array}$ & & \\
\hline Death & $20(13.0 \%)$ & $22(14.4 \%)$ & 0.7 & $-1.4(-9.3$ to 6.4$)$ \\
\hline Unplanned revascularisation & $46(29.9 \%)$ & 19 (12.4\%) & $<0.001$ & 17.5 (8.5 to 26.4$)$ \\
\hline Stroke & $2(1.3 \%)$ & $8(5.2 \%)$ & 0.06 & $-3.9(-8.9$ to 0.06$)$ \\
\hline Reinfarction & $22(14.3 \%)$ & $16(10.5 \%)$ & 0.3 & $3.8(-3.7$ to 11.4$)$ \\
\hline Heart failure & $48(31.2 \%)$ & $40(26.1 \%)$ & 0.3 & $5.0(-5.1$ to 15.1$)$ \\
\hline Composite secondary end point & $89(57.8 \%)$ & $66(43.1 \%)$ & 0.01 & 14.7 (3.5 to 25.5 ) \\
\hline
\end{tabular}

Table 2 shows the one year results. All cause mortality was similar in the conservative arm and the rPCI arm $(13.0 \% \mathrm{v}$ $14.4 \%, \mathrm{p}=0.7, \mathrm{RD}-1.4 \%, 95 \% \mathrm{CI}-9.3$ to 6.4$)$. Reinfarction and clinical heart failure at one year were numerically more common in the conservative arm but the differences were not significant $(14.3 \% v 10.5 \%, \mathrm{p}=0.3, \mathrm{RD} 3.8 \%, 95 \% \mathrm{CI}-3.7$ to 11.4 , and $31.2 \% \vee 26.1 \%, \mathrm{p}=0.3$, RD $5.0 \%, 95 \% \mathrm{CI}-5.1$ to 15.1). There was a strong trend towards fewer strokes in the conservative arm $(1.3 \% \vee 5.2 \%, \mathrm{p}=0.06, \mathrm{RD}-3.9 \%, 95 \% \mathrm{CI}$ -8.9 to 0.06 ). The incidence of the composite secondary end point of death, reinfarction, stroke, unplanned revascularisation, or heart failure was significantly higher in the conservative arm $(57.8 \% \vee 43.1 \%, \mathrm{p}=0.01 \mathrm{RD} 14.7 \%, 95 \%$ CI $3.5 \%$ to $25.5 \%$ ). This was driven by a significantly higher incidence of unplanned revascularisation in the conservative arm $(29.9 \% \vee 12.4 \%, \mathrm{p}<0.001, \mathrm{RD} 17.5 \%, 95 \%$ CI $8.5 \%$ to $26.4 \%)$. All events, with the exception of unplanned subsequent revascularisation, were uncommon after 30 days (table 3).

Most unplanned revascularisations in the conservative arm were carried out in the first 30 days after initial presentation $(\mathrm{n}=31,67 \%)$. Of these, most were performed as emergencies or for urgent clinical indications (two for development of cardiogenic shock after diagnosis of failed fibrinolysis; 11 for reinfarction; 11 for unstable angina; and one for development of ventricular septal defect) and six were for patients with stable symptoms but an adverse exercise tolerance test. Most revascularisations were by PCI $(\mathrm{n}=29)$.

In the rPCI arm, unplanned revascularisation was required in 10 patients during the first 30 days, mostly for reinfarction ( $\mathrm{n}=7$ : five PCI and two CABG). Of these seven patients, three had undergone PCI after the initial coronary angiogram and four had not. Of the other three patients requiring unplanned revascularisation within the first 30 days, one had PCI for post-infarction angina, one had PCI after an adverse exercise tolerance test, and one had CABG for unstable angina. None of these three patients had been treated with PCI after the initial coronary angiography because of normal flow in the infarct related vessel.

Between 30 days and one year, a further 15 patients in the conservative arm ( $10.9 \%$ of those alive at 30 days) and nine in the rPCI arm (6.5\% of those alive at 30 days) underwent unplanned revascularisation as defined in the trial protocol. Table 4 shows details of these patients.

Figure 2 shows survival and fig 3 shows event-free survival at one year.

Four patients in the rPCI arm had unfavourable anatomy for PCI and four patients did not have coronary anatomy visualised. If these eight patients are excluded, the incidence of unplanned revascularisation at one year was numerically higher among the 44 patients who did not have initial PCI to the infarct related vessel ( 42 with TIMI 3 flow, two with TIMI $<3$ flow) than among the 101 patients who underwent PCI to the infarct related vessel irrespective of antegrade flow ( $18.1 \%$ v $7.9 \%, \mathrm{p}=0.07, \mathrm{RD} 10.3 \%, 95 \% \mathrm{CI}-0.8 \%$ to $24.8 \%$ ). This difference was present and significant at 30 days ( $13.6 \%$ $v 3.0 \%, \mathrm{p}=0.02$, RD $10.7 \%, 95 \%$ CI $1.9 \%$ to $24.1 \%$ ).

\section{DISCUSSION}

There seems to be an inherent logic in attempting to achieve patency in the infarct related vessel after acute STEMI, ideally achieving myocardial perfusion at the cellular level at the same time. Therefore, rPCI for failed fibrinolysis is an attractive strategy. Some observational studies have suggested good outcomes with rPCI if normal antegrade flow in the infarct related vessel is achieved quickly and without complication, particularly if ST segment resolution follows. The only previous moderate sized randomised trial designed to address this issue also provides some support for the strategy. In the randomised evaluation of salvage angioplasty with combined utilisation of end points (RESCUE) trial, Ellis et al ${ }^{12}$ reported a borderline significant reduction in the incidence of death or severe heart failure among patients undergoing rPCI for occlusion of the left anterior descending artery after fibrinolytic administration for a first anterior infarction compared with those managed conservatively $(6 \% v 17 \%, \mathrm{p}=0.05)$, although this was not a prespecified end point. ${ }^{12}$ In addition, data from the only two randomised controlled trials with longer term follow up suggest a survival advantage with rPCI. ${ }^{14}$

After the publication of the RESCUE trial, further studies showed that rPCI could be performed with a high degree of technical success and beneficial effects on patient outcomes. ${ }^{469}$ In the study by Ross et $a l^{6}$ of patients undergoing rPCI in the angiographic substudy of GUSTO-1 (global

Table 3 Events at 30 days and one year

\begin{tabular}{|c|c|c|c|c|c|c|}
\hline \multirow[b]{2}{*}{ Event } & \multicolumn{2}{|l|}{30 days } & \multicolumn{2}{|c|}{30 days-one year* } & \multicolumn{2}{|l|}{ One year } \\
\hline & Conservative & $\mathrm{rPCl}$ & Conservative & $\mathrm{rPCl}$ & Conservative & $\mathrm{rPCl}$ \\
\hline Death & $17(11.0 \%)$ & $15(9.8 \%)$ & $3(2.2 \%)$ & $7(5.1 \%)$ & $20(13.0 \%)$ & $22(14.4)$ \\
\hline Unplanned revascularisation & $31(20.1 \%)$ & $10(6.5 \%)$ & $15(10.9 \%)$ & $9(6.5 \%)$ & $46(29.9 \%)$ & 19 (12.4\%) \\
\hline Stroke & $1(0.6 \%)$ & $7(4.6 \%)$ & $1(0.7 \%)$ & $1(0.7 \%)$ & $2(1.3 \%)$ & $8(5.2 \%)$ \\
\hline Reinfarction & $16(10.4 \%)$ & $11(7.2 \%)$ & $6(4.4 \%)$ & $5(3.6 \%)$ & $22(14.3 \%)$ & $16(10.5 \%)$ \\
\hline Heart failure & $46(29.9 \%)$ & $37(24.2 \%)$ & $2(1.5 \%)$ & $3(2.2 \%)$ & $48(31.2 \%)$ & $40(26.1 \%)$ \\
\hline
\end{tabular}


Table 4 Unplanned revascularisation between 30 days and one year

\begin{tabular}{|c|c|c|c|}
\hline \multirow[b]{2}{*}{ Treatment arm and event } & \multicolumn{2}{|c|}{$\begin{array}{l}\text { Mode of } \\
\text { revascularisation }\end{array}$} & \multirow[b]{2}{*}{ Details } \\
\hline & $\mathrm{PCl}$ & CABG & \\
\hline $\begin{array}{l}\text { Conservative }(n=15) \\
\text { Emergency readmission with ACS }(n=8)\end{array}$ & 5 & 3 & $\begin{array}{l}4 \Pi \text { negative } A C S \text { receiving urgent } \mathrm{PCl} ; 1 \Pi \text { negative } \mathrm{ACS} \text { receiving urgent } \mathrm{CABG} ; 2 \mathrm{TT} \\
\text { positive } \mathrm{ACS} \text { receiving urgent } \mathrm{CABG} ; 1 \text { STEMI (different territory) receiving urgent } \mathrm{PCl}\end{array}$ \\
\hline Other $(n=7)$ & 4 & 3 & $\begin{array}{l}3 \text { undergoing CA during index admission for postinfarction angina or positive ETT but } \\
\text { revascularisation deferred: } 1 \text { interval CABG, } 2 \text { interval } P C l ; 4 \text { undergoing CA after } \\
\text { discharge, followed by revascularisation: } 1 \text { postinfarction angina undergoing CA then } \\
C A B G, 2 \text { post-infarction angina undergoing } C A \text { then } P C l, 1 \text { adverse ETT at } 6 \text { weeks } \\
\text { detained for } C A \text { and urgent } C A B G\end{array}$ \\
\hline $\begin{array}{l}\mathrm{rPCl}(\mathrm{n}=9 \text { ) } \\
\text { Emergency readmission with ACS (no } \\
\text { revascularisation during index admission, } \\
\text { but triple vessel disease, } n=4 \text { ) }\end{array}$ & 1 & 3 & $\begin{array}{l}1 \text { discharged after negative } E T T \text { readmitted with } T \text { negative } A C S \text { receiving } C A B G ; 1 T \\
\text { positive } A C S \text { receiving } P C I \text { (not IRV); } 2 \text { on elective list for } C A B G \text { readmitted with } A C S \\
\text { (1 STEMI in different territory from original; } 1 \mathrm{TT} \text { negative } A C S \text { ) receiving urgent } C A B G\end{array}$ \\
\hline $\begin{array}{l}\text { Emergency readmission with ACS after } \\
\mathrm{PCI} \text { to IRV during index admission }(n=4)\end{array}$ & 3 & 1 & $\begin{array}{l}1 \mathrm{TT} \text { negative } \mathrm{ACS} \text { receiving } C A B G ; 1 \text { further STEMI receiving } \mathrm{PCI} \text { to new lesion within } \\
\mathrm{IRV} ; 1 \text { TI negative } \mathrm{ACS} \text { receiving } \mathrm{PCI} \text { to new lesion within IRV; } 1 \text { STEMI receiving } \mathrm{PCI} \text { to } \\
\text { different vessel }\end{array}$ \\
\hline Other $(n=1)$ & 0 & 1 & 1 ISR receiving elective CABG \\
\hline
\end{tabular}

utilisation of streptokinase and tissue plasminogen activator for occluded coronary arteries), the intervention resulted in superior left ventricular function and 30 day mortality compared with patients treated conservatively after angiography provided evidence of a persistently occluded infarct related vessel after thrombolytic administration. In addition, this study contradicted the findings of the TIMI-IIA ${ }^{15}$ and SAMI (streptokinase angioplasty myocardial infarction) ${ }^{16}$ trials, which had unacceptably high rates of non-coronary complications after angioplasty in the context of prior administration of a thrombolytic. Small retrospective analyses have suggested that stenting in rPCI is feasible, safe, and associated with better angiographic results and possibly improved patient outcome. ${ }^{17} 18$ In addition, transfer of selected patients receiving a thrombolytic with a view to rescue angioplasty has been shown to be relatively safe and associated with a favourable outcome. ${ }^{19} 20$

However, in MERLIN, a contemporary randomised trial of rPCI versus conservative medical treatment for failed fibrinolysis, the benefits of rPCI were small. We have shown that rPCI has a high success rate in terms of restoring normal antegrade flow in an occluded or partially occluded vessel. Successful catheterisation laboratory outcomes were also achieved in patients with TIMI 3 flow at initial angiography but who had a critical coronary artery stenosis. Despite this, rPCI did not confer a survival advantage by 30 days. Two of the patients who died in the rPCI arm died of non-coronary causes, but even if these two patients are excluded from the analysis, the difference in 30 day mortality is not significant.
The 30 day mortality in the conservative arm was lower than anticipated from our previous experience and from literature published before initiation of the study. ${ }^{21}{ }^{22}$ The 30 day mortality in the rescue angioplasty arm was also higher than expected, particularly, and surprisingly, in the patients who achieved normal antegrade flow after rescue angioplasty. In our previous experience, patients with TIMI 3 flow on leaving the catheterisation laboratory, irrespective of whether angioplasty had been performed, had a 30 day mortality of $6.9 \%{ }^{3}$ In MERLIN, the equivalent figure was $9.2 \%$. In addition to the lack of early survival advantage, rPCI was not associated with a survival advantage by one year compared with the conservatively managed cohort. In fact, numerically more patients died between 30 days and one year of follow up in the rPCI arm, although the overall number of events after 30 days was low. Although follow up to three years is planned, it is extremely unlikely that the Kaplan-Meier survival curves will diverge significantly.

Our previous experience suggested that certain angiographic characteristics, particularly a high grade residual stenosis or the presence of visible thrombus, may be used to predict early reinfarction or unstable angina in patients with normal flow in the infarct related vessel soon after the administration of a fibrinolytic and that the presence of these features is associated with a ninefold incidence of early adverse events. ${ }^{23}$ On the basis of our previous experience, the operator felt that all but one of the 42 patients in the rPCI cohort with TIMI 3 flow in the infarct related vessel who did not undergo PCI to the infarct related vessel at that stage had

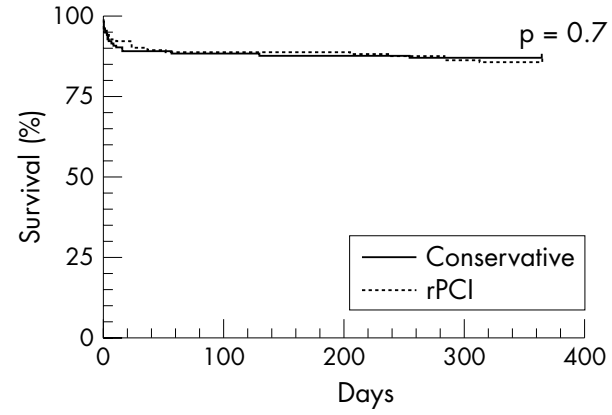

Figure 2 One year survival.

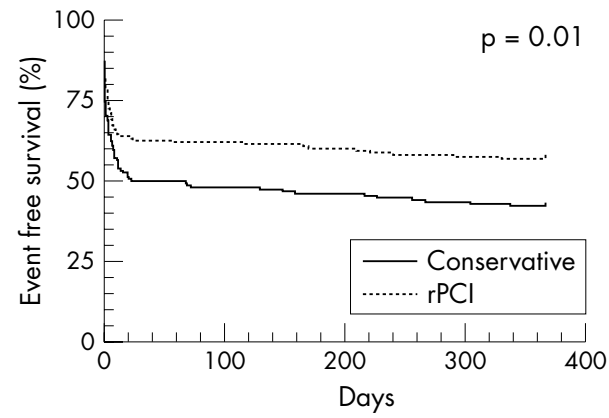

Figure 3 One year event-free survival. 
a low risk of reocclusion. Nonetheless, patients in the rPCI arm with normal antegrade flow at initial angiography and no high risk features who did not undergo immediate PCI had an $18.1 \%$ incidence of unplanned revascularisation by one year. It is possible that this may have been reduced by performing angioplasty to all infarct related vessels in the rPCI cohort at the time of initial coronary angiography. It is also possible that the low rate of coronary stenting $(50.3 \%$ as befits an infarct angioplasty trial that started in 1999) accounts for some episodes of reinfarction and unplanned revascularisation in the rPCI cohort. A higher rate of glycoprotein IIb/IIIa use (3.3\% in the trial) may have reduced complications in the rPCI cohort, but we believe that the rate of major haemorrhagic complications with full dose glycoprotein IIb/IIIa inhibitors and full dose streptokinase is prohibitively high. ${ }^{24}$ However, we cannot exclude the possibility that intervention in every case might have reduced the high rate of final TIMI 3 flow we observed in the rPCI cohort, which is considerably higher than that observed among patients undergoing rPCI in the GUSTO-1 trial $(67.7 \%)^{6}{ }^{6}$

There are several possible explanations for the lower than anticipated mortality in the conservative arm. Firstly, the policy of actively seeking patients with persistent ST elevation just one hour after the initiation of thrombolytic treatment identifies a heterogeneous group of patients, including some who will reperfuse on clinical criteria within the next 30-60 minutes and those with relatively small haemodynamically insignificant inferior myocardial infarction.

Secondly, patients in the conservative arm underwent rigorous post-infarction risk stratification, resulting in a $20 \%$ rate of unplanned revascularisation by 30 days. Unsurprisingly, this was more common in the revascularisation centre than in the referral hospitals (24\% v 16\%). For UK practice, this is a high rate of revascularisation within 30 days of STEMI. In PRAIS-UK (prospective registry of acute ischaemic syndromes in the UK), ${ }^{25}$ which included patients with acute coronary syndromes but without ST segment elevation, the revascularisation rate by six months was $15 \%$. Patients presenting with ST segment elevation may be expected to have a lower rate of revascularisation than this, but our cohort of patients had a higher rate of revascularisation within a shorter time frame from the initial event.

Thirdly, earlier studies may have overestimated the risk of patients with persistent ST segment elevation after thrombolytic treatment, with the result that our trial is underpowered to detect significant differences in mortality. Interestingly, in the study by de Lemos et al, ${ }^{26}$ the mortality among patients with no ST segment resolution 60 minutes after initiation of thrombolytic treatment was $7.7 \%$ at 30 days and $10.7 \%$ at one year, consistent with the results seen in MERLIN.

We accept that our original power calculation appears, in hindsight, to have been optimistic in estimating the mortality reduction that may be observed with a strategy of emergency coronary angiography and rPCI where appropriate compared with conservative treatment. Nonetheless, it was based on a careful review of the available literature, a process that found wide variation in clinical trials. In the first PRAGUE study (primary angioplasty in patients transferred from general community hospitals to specialised PTCA units with or without emergency thrombolysis), Widimsky et al ${ }^{19}$ reported a high $(23 \%)$ incidence of the combined end point of death, reinfarction, and stroke among 99 patients receiving a thrombolytic and remaining in the admitting hospital, even though presentation within six hours of symptom onset was required and cardiogenic shock was excluded. This exceeds the incidence $(19 \%)$ of the same end point at 30 days in the MERLIN conservative group, even though our conservative group includes higher risk patients on the basis of longer pain to thrombolysis times, older age, and the requirement of failed fibrinolysis for trial entry.

Patients offered urgent rPCI in the MERLIN trial did have a significant reduction in the 30 day incidence of the combined end point of death, reinfarction, stroke, unplanned revascularisation, or heart failure and this is maintained at one year. This advantage is driven almost exclusively by a highly significant reduction in the requirement for unplanned revascularisation. It is debatable whether this end point alone justifies a default rPCI approach to the diagnosis of failed fibrinolysis. In favour of the rPCI approach is that most unplanned revascularisation, particularly in the early phase, is for reinfarction or post-infarction unstable angina. In our view, the prevention of reinfarction is important, given that reinfarction is associated with extremely high in-hospital mortality. In DANAMI-2 (the second Danish multicentre randomised study on fibrinolytic therapy versus acute coronary angioplasty in acute myocardial infarction), ${ }^{27}$ the mortality associated with reinfarction was $24.2 \%$. Mortality as high as $41 \%$ has been reported. ${ }^{28}{ }^{29}$ Even in reports where the mortality associated with reinfarction was much lower than this, ${ }^{30}$ reinfarction was still associated with an early mortality three times higher than that among patients not sustaining reinfarction. In many of these studies, it is not clear how reinfarction was treated. However, there is evidence to suggest that patients presenting with STEMI who subsequently sustain reinfarction have a much lower risk of dying if revascularisation is performed than if they are treated medically, even if revascularisation is not performed in the emergency setting of reinfarction. ${ }^{28}$

We do not believe that the reduced requirement for revascularisation in the rPCI arm was entirely predictable. The trial did not mandate PCI for all patients in the rPCI arm but rather it was a trial of angiographically driven treatment versus conservative management. In addition, further intervention to non-infarct related vessels (possibly driven by the "occulostenotic reflex") and further revascularisation for restenosis are possible.

The results of the MERLIN trial are widely applicable to patients receiving streptokinase fibrinolytic for STEMI. There was no age limit to trial entry (although few extreme elderly patients were enrolled) and almost $70 \%$ of all eligible patients at the revascularisation centre were entered into the trial, with most non-randomisation among eligible patients being due to failure to obtain informed consent. Undoubtedly, this has resulted in a very different cohort of patients from that in the RESCUE trial. The high incidence of important clinical end points among the MERLIN trial patients is indicative of a population more representative of the patients with failed fibrinolysis seen in daily clinical practice. The RESCUE trial almost certainly enrolled a lower risk group, even though all had sustained anterior STEMI and all were required to have left anterior descending coronary artery occlusion before randomisation (table 5). In the rPCI arm of the RESCUE trial, the incidences of death and heart failure at 30 days were both very low $(5.1 \%$ and $1.3 \%)$, despite final procedural success being defined as the presence of TIMI 2 or TIMI 3 flow (achieved in 92\%), limited use of stents and intra-aortic balloon pumps, and no glycoprotein IIb/IIIa inhibition. In addition, the recruitment rate in RESCUE was 2.4 patients for each centre yearly versus 13.9 patients for each centre yearly with anterior myocardial infarction and failed reperfusion in MERLIN, which suggests a highly selective approach to patient recruitment in RESCUE.

In keeping with previous studies, ${ }^{2-6}$ our experience is that failed rPCI is associated with an extremely poor prognosis. Although the number of patients in whom rPCI is technically unsuccessful is small (6\% failure in those with suitable anatomy in MERLIN), the morbidity and mortality in this 


\begin{tabular}{|c|c|c|c|}
\hline & MERLIN all patients & $\begin{array}{l}\text { MERLIN patients with } \\
\text { anterior MI }\end{array}$ & $\begin{array}{l}\text { RESCUE trial patients } \\
\text { intervention arm }\end{array}$ \\
\hline Number & 307 & 136 & 78 \\
\hline Age (years) & $62.8(11.1)$ & $62.3(11.4)$ & $59(11)$ \\
\hline Chest pain to lysis time (min) & $175(108)$ & $194(126)$ & Unknown* \\
\hline Time to angioplasty (min) & $\begin{array}{l}327 \text { (121) (rPCl arm } \\
\text { only) }\end{array}$ & $\begin{array}{l}353 \text { (135) (rPCl arm } \\
\text { only) }\end{array}$ & $270(114)$ \\
\hline Previous MI & $12.1 \%$ & $13.2 \%$ & 0 \\
\hline Multivessel disease & $\begin{array}{l}76 \% \text { (rPCl arm only, } \\
n=153 \text { ) }\end{array}$ & $\begin{array}{l}69 \% \text { (rPCl arm only, } \\
n=74)\end{array}$ & $34 \%$ \\
\hline 30 day heart failure & $27.0 \%$ & $33.8 \%$ & $1.3 \%$ \\
\hline 30 day death & $10.4 \%$ & $17.6 \%$ & $5.1 \%$ \\
\hline 30 day heart failure or death & $31.9 \%$ & $44.1 \%$ & $6.4 \%$ \\
\hline \multicolumn{4}{|c|}{$\begin{array}{l}\text { *Catheterisation was done }<6 \text { hour after pain onset (discretionary } 8 \text { hours) and at least } 90 \text { minutes after initiation } \\
\text { of lysis. } \\
\text { MERLIN, Middlesbrough early revascularisation to limit infarction; RESCUE, randomised evaluation of salvage } \\
\text { angioplasty with combined utilisation of end points. }\end{array}$} \\
\hline
\end{tabular}

group may exceed those in patients with failed fibrinolysis managed conservatively. Some features seem to predict a failed rPCI procedure. We have previously found that the presence of diabetes, prolonged time from symptom onset to administration of a fibrinolytic, and advanced age are associated with a failed rPCI procedure and therefore an adverse outcome. ${ }^{31}$ However, these features are in general associated with an adverse outcome after STEMI and therefore their presence should perhaps prompt a more aggressive rather than a less aggressive approach. In addition, there is a subgroup of patients in whom antegrade flow is restored at the time of PCI but who have persistent ST segment elevation on the 12 lead ECG. These patients probably have microvascular damage and it is unclear how they should be managed.

We do not know whether the presence of chest pain as a requirement for trial entry would have resulted in a higher risk cohort of patients, potentially with more to gain from rPCI. However, our large experience of infarct angioplasty, before and including MERLIN, is that the presence of chest pain is not a reliable predictor of persistent arterial occlusion and that the absence of chest pain is a very poor indicator of arterial patency. This is consistent with the observations of other investigators. ${ }^{32}$ We recorded the presence or absence of chest pain in all MERLIN trial patients at the time of randomisation. We previously reported ${ }^{13}$ that in the rescue arm $53 \%$ of those who were pain-free at randomisation had inadequate antegrade flow in the infarct related vessel and that $38 \%$ of those in pain at randomisation had normal antegrade flow in the infarct related vessel. Furthermore, $43 \%$ of patients in the rescue arm who were pain-free immediately before the coronary angiogram had inadequate antegrade flow in the infarct related vessel and $26 \%$ of those in pain immediately before the coronary angiogram had normal antegrade flow in the infarct related vessel. Therefore, reliance on the presence or absence of ongoing symptoms would have resulted in a large number of incorrect diagnoses and, in particular, a large number of incorrect diagnoses of successful fibrinolysis.

In conclusion, we have not observed a mortality advantage at one year with a strategy of rPCI compared with medical treatment. Any advantage in the rPCI arm observed at one year is almost exclusively due to a lower requirement for further revascularisation compared with the medically treated group. This advantage is gained at the expense of more strokes and a greater requirement for blood transfusions in the initial phase. A routine policy of rPCI is therefore not supported by these data as long as patients managed conservatively are treated aggressively for post-infarction angina or reinfarction. These results may not be applicable to patients with failed fibrinolysis after administration of fibrin specific agents.

\section{ACKNOWLEDGEMENTS}

We are grateful to Guidant, Boston Scientific, Jomed, and Datascope for providing financial support.

\section{Authors' affiliations}

A G C Sutton, P G Campbell, R Graham, D J A Price, E D Grech, J A Hall, A A Harcombe, R A Wright, M J Stewart, A Davies, N J Linker, M A de Belder, The James Cook University Hospital, Middlesbrough, UK J C Gray, University of Newcastle, Newcastle, UK

R H Smith, A Shyam-Sundar, University Hospital of North Tees, Stockton-on-Tees, UK

J J Murphy, Darlington Memorial Hospital, Darlington, UK

\section{APPENDIX}

Steering Group: Mark A de Belder, Andrew G C Sutton (The James Cook University Hospital), Roger H Smith (University Hospital of North Tees), Jerry M Murphy (Darlington Memorial Hospital), Janine C Gray (University of Newcastle-upon-Tyne).

Data and Safety Monitoring Committee: Rudy Bilous, Steve Jones (Department of Medicine, The James Cook University Hospital), Martyn Farrer (Sunderland General Hospital), Peter Kelly (Biomedical Statistics Department, University of Teesside).

Research Assistants: Andrew Gardiner, Sharon Kamara, Nicky Cunningham, Bev Atkinson, Maggie Frost, Rachel Blackmore

\section{REFERENCES}

1 GUSTO Angiographic Investigators. The effects of tissue plasminogen activator, streptokinase, or both on coronary-artery patency, ventricular function, and survival after acute myocardial infarction. N Engl J Med 1993;329:1615-22

2 Gorfinkel HJ, Berger SM, Klaus AP, et al. Rescue angioplasty in failed thrombolysis in acute myocardial infarction: a community hospital experience. J Invasive Cardiol 1997;9:83-7.

3 Sutton AGC, Campbell PG, Grech ED, et al. Failure of thrombolysis: experience with a policy of early angiography and rescue angioplasty for electrocardiographic evidence of failed thrombolysis. Heart 2000:84:197-204.

4 Gibson CM, Cannon CP, Greene RM, et al. Rescue angioplasty in the thrombolysis in myocardial infarction (TIMI) 4 trial. Am J Cardiol 1997;80:21-6.

5 Balachandran KP, Miller J, Pell AC, et al. Rescue percutaneous coronary intervention for failed thrombolysis: results from a district general hospital. Postgrad Med J 2002;78:330-4.

6 Ross AM, Lundergan CF, Rohrbeck SC, et al. Rescue angioplasty after failed thrombolysis: technical and clinical outcomes in a large thrombolysis trial. GUSTO-1 Angiographic Investigators. Global utilization of streptokinase and tissue plasminogen activator for occluded coronary arteries. J Am Coll Cardiol 1998;31:151 1-7. 
7 Oude Ophius AJM, Bar FW, Vermeer F, et al. Early referral for intentional rescue PTCA after initiation of thrombolytic therapy in patients admitted to a community hospital because of a large acute myocardial infarction. Am Heart $J$ 1999; 137:846-53.

8 Schweiger MJ, Cannon CP, Murphy SA, et al. Early coronary intervention following pharmacologic therapy for acute myocardial infarction (the combined TIMI 1OB-TIMI 14 experience). Am J Cardiol 2001;88:831-6.

9 Bar F, Vainer J, Stevenhagen J, et al. Ten-year experience with early angioplasty in 759 patients with acute myocardial infarction. J Am Coll Cardiol 2000:36:51-8.

10 Adamian MG, Stone GW, Mehran R, et al. Have the outcomes of rescue angioplasty after failed thrombolytic therapy in acute myocardial infarction improved in the stent era? J Am Coll Cardiol 2003;39:309A.

11 Juliard J-M, Himbert D, Cristofini $P$, et al. A matched comparison of the combination of prehospital thrombolysis and standby rescue angioplasty with primary angioplasty. Am J Cardiol 1999;83:305-10.

12 Ellis SG, da Silva ER, Heyndrickx G, et al. Randomized comparison of rescue angioplasty with conservative management of patients with early failure of thrombolysis for acute anterior myocardial infarction. Circulation 1994;90:2280-4.

13 Sutton AGC, Campbell PG, Graham R, et al. A Randomized trial of rescue angioplasty versus a conservative approach for failed fibrinolysis in STsegment elevation myocardial infarction. The Middlesbrough early revascularization to limit infarction (MERLIN) trial. J Am Coll Cardiol 2004:44:287-96.

14 Ellis SG, da Silva ER, Spaulding CM, et al. Review of immediate angioplasty after fibrinolytic therapy for acute myocardial infarction: Insights from the RESCUE I, RESCUE II, and other contemporary clinical experiences. Am Heart J 2000:139:1046-53.

15 TIMI Study Group. Comparison of invasive and conservative strategies after treatment with intravenous tissue plasminogen activator in acute myocardial infarction. Results of the thrombolysis in myocardial infarction (TIMI) phase II trial. N Engl J Med 1989;320:618-27.

16 O'Neill WW, Weintraub R, Grines CL, et al. A prospective, placebocontrolled, randomized trial of intravenous streptokinase and angioplasty versus lone angioplasty therapy of acute myocardial infarction. Circulation 1992;86:1710-7

17 Cafri C, Denktas AE, Crystal E, et al. Contribution of stenting to the results of rescue PTCA. Catheter Cardiovasc Interv 1999;47:411-4.

18 Moreno R, Garcia E, Abeytua M, et al. Coronary stenting during rescue angioplasty after failed thrombolysis. Catheter Cardiovasc Interv 1999:47:1-5

19 Widimsky P, Groch L, Zelizko M, et al. Multicentre randomized trial comparing transport to primary angioplasty vs immediate thrombolysis vs combined strategy for patients with acute myocardial infarction presenting to a community hospital without a catheterization laboratory. The PRAGUE study. Eur Heart J 2000;21:823-31.

20 Vermeer F, Oude Ophius AJM, vd Berg EJ, et al. Prospective randomised comparison between thrombolysis, rescue PTCA, and primary PTCA in patients with extensive myocardial infarction admitted to a hospital without PTCA facilities: the LIMI study, a safety and feasibility study. Heart 1999:82:426-31

21 Purcell IF, Newall N, Farrer M. Change in ST segment elevation 60 minutes after thrombolytic initiation predicts clinical outcome as accurately as later electrocardiographic changes. Heart 1997;78:465-71.

22 Schroder R, Wegscheider K, Schroder K, et al. Extent of early ST segment elevation resolution: a strong predictor of outcome in patients with acute myocardial infarction and a sensitive measure to compare thrombolytic regimens. A substudy of the international joint efficacy comparison of thrombolytics (INJECT) trial. J Am Coll Cardiol 1995;26:1657-64

23 Grech ED, Sutton AGC, Campbell PG, et al. Reappraising the role of immediate intervention following thrombolytic recanalization in acute myocardial infarction. Am J Cardiol 2000;86:400-5.

24 Antman EM, Giugliano RP, Gibson CM, et al. Abciximab facilitates the rate and extent of thrombolysis: results of the thrombolysis in myocardial infarction (TIMI) 14 trial. The TIMI 14 Investigators. Circulation 1999:99:2720-32.

25 Collinson J, Flather MD, Fox KA, et al. Clinical outcomes, risk stratification and practice patterns of unstable angina and myocardial infarction without ST elevation: prospective registry of acute ischaemic syndromes in the UK (PRAIS UK). Eur Heart J 2000;21:1450-7.

26 De Lemos JA, Antman EM, Giugliano RP, et al. Comparison of a 60- versus 90-minute determination of ST-segment resolution after thrombolytic therapy for acute myocardial infarction. In TIME-II Investigators. Intravenous nPA for treatment of infarcting myocardium early-II. Am J Cardiol 2000;86:1235-7.

27 Andersen HR, Nielsen TT, Rasmussen K, et al. A comparison of coronary angioplasty with fibrinolytic therapy in acute myocardial infarction. N Engl J Med 2003;349:733-42.

28 Gibson CM, Karha J, Murphy SA, et al. Early and long-term clinical outcomes associated with reinfarction following fibrinolytic administration in the thrombolysis in myocardial infarction trials. J Am Coll Cardiol 2003:42:7-16.

29 Donges K, Schiele R, Gitt A, et al. Incidence, determinants, and clinical course of reinfarction in-hospital after index acute myocardial infarction (results from the pooled data of the maximal individual therapy in acute myocardial infarction [MITRA], and the myocardial infarction registry [MIR]). Am J Cardiol 2001;87:1039-44.
30 Hudson MP, Granger CB, Topol EJ, et al. Early reinfarction after fibrinolysis: experience from the global utilization of streptokinase and tissue plasminogen activator (alteplase) for occluded coronary arteries (GUSTO I) and global use of strategies to open occluded coronary arteries (GUSTO III) trials. Circulation 2001:104:1229-35.

31 Sutton AGC, Campbell PG, Hall JA, et al. Rescue angioplasty for failed fibrinolysis: can we identify those patients who do not benefit [abstract]? Eur Heart J 2002;23(suppl):24.

32 Nicolau JC, Lorga AM, Garzon SA, et al. Clinical and laboratory signs of reperfusion: are they reliable? Int J Cardiol 1989;25:313-20.

\section{WEB TOP 10}

www.heartinl.com

These articles scored the most hits on Heart's website during July 2005

1 Primary percutaneous coronary intervention in acute myocardial infarction: time, time, and time!

PG Steg, J-M Juliard

August 2005;91:993-4. (Editorial)

2 The ECG in acute coronary syndromes: new tricks from an old dog

HS Gurm, EJ Topol

July 2005:91:851-3. (Editorial)

3 Helicobacter pylori and atrial fibrillation: a possible pathogenic link

AS Montenero, N Mollichelli, F Zumbo, A Antonelli, A Dolci, $M$ Barberis, C Sirolla, T Staine, L Fiocca, N Bruno, S O'Connor

July 2005;91:960-1. (Scientific letter)

4 Systematic review of multidisciplinary interventions in heart failure

R Holland, J Battersby, I Harvey, E Lenaghan, J Smith, L Hay July 2005;91:899-906. (Cardiovascular medicine)

5 Definition of acute coronary syndrome

IN Findlay, $A D$ Cunningham

July 2005;91:857-9. (Viewpoint)

$6 \mathrm{~N}$-acetylcysteine for prevention of radiocontrast induced nephrotoxicity: the importance of dose and route of administration

S J Shalansky, G E Pate, A Levin, J G Webb

August 2005;91:997-9. (Editorial)

7 Coronary angiography in the angioplasty era: projections with a meaning

C Di Mario, N Sutaria

July 2005;91:968-76. (Education in Heart)

8 Cardiac imaging in coronary artery disease: differing modalities

JD Schuiif, L Shaw, W Wiins, HJ Lamb, D Poldermans, A de Roos, EE van der Wall, JJ Bax

August 2005;91:1110-17. (Education in Heart)

9 Instructive ECG series in massive bilateral pulmonary embolism

ASH Cheng, A Money-Kyrle

March 2005;91:860-2. (Featured case report)

10 Assessment of diastolic function: what the general cardiologist needs to know

PM Mottram, TH Marwick

May 2005;91:681-95. (Education in Heart)

Visit the Heart website for hyperlinks to these articles, by clicking on "Top 10 papers"

www.heartinl.com 